\title{
Students creative workshop as human resource management in municipal facilities and urban development
}

\author{
Olga Solnyshkova ${ }^{1, *}$ and Ekaterina Boiko ${ }^{2}$ \\ ${ }^{1}$ Novosibirsk State University of Architecture and Civil Engineering (SIBSTRIN), Leningradskaya \\ str., 113, Novosibirsk, 630089, Russia \\ ${ }^{2}$ Siberian Institute of Management - the branch of the Presidential Academy of National Economy \\ and Public Administration (SIM RANEPA), 630102 Novosibirsk, Russia
}

\begin{abstract}
The experience of formation of key students' competences at higher education civil engineering institutes by means of participation in student's creative workshops is analyzed in the article. The hierarchical structure of the creative workshop at the NSACU (Sibstrin) is given and the possibilities of completing students' professional tasks that require a high level of responsibility within the development of electronic learning resources are shown.
\end{abstract}

\section{Introduction}

The main learning goal in a higher education institute is the development of the necessary key competences in professional activity. Gained knowledge and abilities allow carrying out all components of future profession with the high quality and utmost efforts. At the same time, students' higher learning of civil engineering is directed on obtaining competences of innovative sections of the construction industry, such as high-rise and wide-span constructions, their reconstruction and monitoring of their use [1]. But the acquisition of such competences is possible not only at the students' immersion into the domain area, but also during the creation of conditions for work activity imitation.

The future builder should acquire skills of professional project activities within the system approach using to the development of engineering technology solutions in construction. Only such an expert can carry out professional actions on objects of high-rise construction since such objects require modern knowledge, management decision-making skills, a high degree of subordinates responsibility and a quick response to emergencies at interaction of various economic, social, technical factors.

\section{Materials and methods}

The graduate of a civil engineering higher education institute has to learn a creative engineering design to consider conditions of the construction engineering existing, to apply

\footnotetext{
* Corresponding author: michmacha@mail.ru
} 
the most effective techniques, the latest technologies and materials in practice $[2,3]$. Therefore the introduction of students' project activities into the learning process is the main condition of development of technological competences and competitiveness of the graduate of a higher education institute in construction.

Only profession knowledge and abilities are not enough for a student in a future, it is necessary to form a creative component of the future specialist which includes the ability to the innovative activity and to the professional growth. In order to train specialists to construct highly-engineered and high - rise buildings it is necessary to consider the fact that the future specialist trained such a way becomes an universal one in many respects and therefore, rather demanded in the professional community. It is also important to give an ability of reaction to the change of activity's real conditions, mobility and competitiveness $[4,5]$.

The importance of ensuring the graduate's effective professional activity sets a task of providing high technological effectiveness of the learning process on the basis of the innovative learning technologies introduction as the didactic system works in a constantly renew mode.

A higher learning in construction provides a consecutive accumulation of the student's knowledge, but at the same time it pays attention to the development of consciousness, a reflection of the trainee insufficiently and often has a fragmentary character [6].

It is necessary to apply the most effective pedagogical approaches in their interaction to the process of students' background at a higher education institute in construction. The integration of professional knowledge areas allows revealing new prospects for the organization of teaching process and transferring it to the self-education process. The strengthening of the student-centered education renders a self-education process reasonable that is important if you want to continue the increase of a professional level in education after graduating from the higher education institute. At the same time it is necessary to upgrade contents, forms and methods of students' vocational training as future builders. Besides, the student-centered education in a higher education institute in construction is inefficient without targeted individualization of the project and creative activities directed to self-education of future builders' competitiveness [7,8].

In order to achieve high-quality vocational training of the future specialists with high competitiveness in construction it is necessary to meet the following conditions:

1. The immersion of the student to the professional area not only by his acquaintance to profession elements at lectures, laboratory and practical classes is necessary, during practical and job training, but also the implementation of psychological and pedagogical follow-up of different types of students' individual work.

2. The teacher should focus students on the independent search of information, necessary for their learning, in various physical or electronic media, only directing and correcting the search process.

3. It is important to motivate the student on self-education and individual improvement by involving in various project and creative tasks, professional contests, the interuniversity subject Olympiads.

4. It is necessary to acquaint the students with external criteria for the assessment of performance at the creative work organization, also to designate the components of the overall performance, to show elements of scientific novelty, practical importance.

Above-mentioned conditions can be created in various creative students' unions of professional orientation. Creative workshops, student's design studios, scientific research and practice groups under the leadership of lecturers are the examples of the student's unions which allow diversifying a class activity and directing the students' interests to professional self-education. The creative workshop of the Geo-S electronic learning resources on the basis of the engineering geodesy department of the Novosibirsk State 
Architectural and Construction University (Sibstrin) can be an example of student's union under the leadership of the teacher.

The usage of students in vocational training of the architectural and construction directions of the interactive electronic learning resources created with their participation has allowed proving the making of a student's creative workshop which is functioning at the moment.

As we can see from the figure above the head of a creative workshop is the teacher (one of its authors). Pedagogical follow-up and the organization of topical advisement on the electronic learning resources creation, communication between students, as in groups, and individually belongs to duties of a workshop head. Besides, the creative workshop head creates a series of tasks which solution is possible by means of a creative workshop, also organizes an external advisement of project teams of students by other lecturers.

From the student's community the management is performed by the leading coordinator of a workshop (usually the senior student having experience in projects of a workshop and who has proved to be the good project supervisor). Coordination of work of project teams, the decision of the simplest disputes, the organization of information distribution to the members of a creative workshop, correspondence with hosts of professional skill competitions, conferences and coordination of drafting of reports on such competitions and conferences belongs to his duties. Also an important function of the leading coordinator of a creative workshop is control of work of project teams. Work in a creative workshop on an electronic learning resource is conducted by the project team of students [9-12].

For the development of electronic learning resources the working group is formed by the head of an electronic learning resource (the teacher of the discipline due to which this resource is created) where there are programmers, designers, artists, animators, photo and video operators, sound editors. The project coordinator is at the head of the project team; usually this is the student who has proved to be the good duty-holder and shows leadership skills in the development of an electronic learning resource.

The project coordinator is the head of the team and responsible before the leading coordinator. He regulates the project implementation process, actively communicates with coordinators of other projects and with other duty-holders who are necessary for various advisements on the project.

The delegation of responsibility and initiative develops the qualities necessary for the future specialist. During the work with electronic resources, students master new software products, graphic packages and databases. There is an exchange of abilities, the presentations of author's fragments of design and animation.

Each innovation consideration in electronic learning resources from students is studied carefully, if necessary advisement from lecturers of a higher education institute is requested.

The students working group carries out the work on an electronic learning resource with the teacher (further EER) gradually, according to the earlier prepared plan.

Further we will consider development stages of a standard learning resource:

1. The development of the pedagogical purposes, tasks, degrees of the future electronic resource interactivity.

2. The selection of the developers' team as the students specializing in different types of work.

3. The distribution of duties among the team members, the definition of the project coordinator, the designation hierarchy of team, work scheduling.

4. The determination of the content and an electronic resource structure.

5. The selection of the software for the electronic learning resource development.

6. The preparation of the EER prototype.

7. Filling a prototype of the EER with theory and practice is made under the direct 
control of the lecturer.

8. The development of the EER control and estimation block.

9. The development of design of the EER.

10. The pilot testing of the EER according to teachers and students.

11. The preparation of documents for the EER registration.

12. The development of recommendations for the EER application in the learning process, the start in replication and in the learning process.

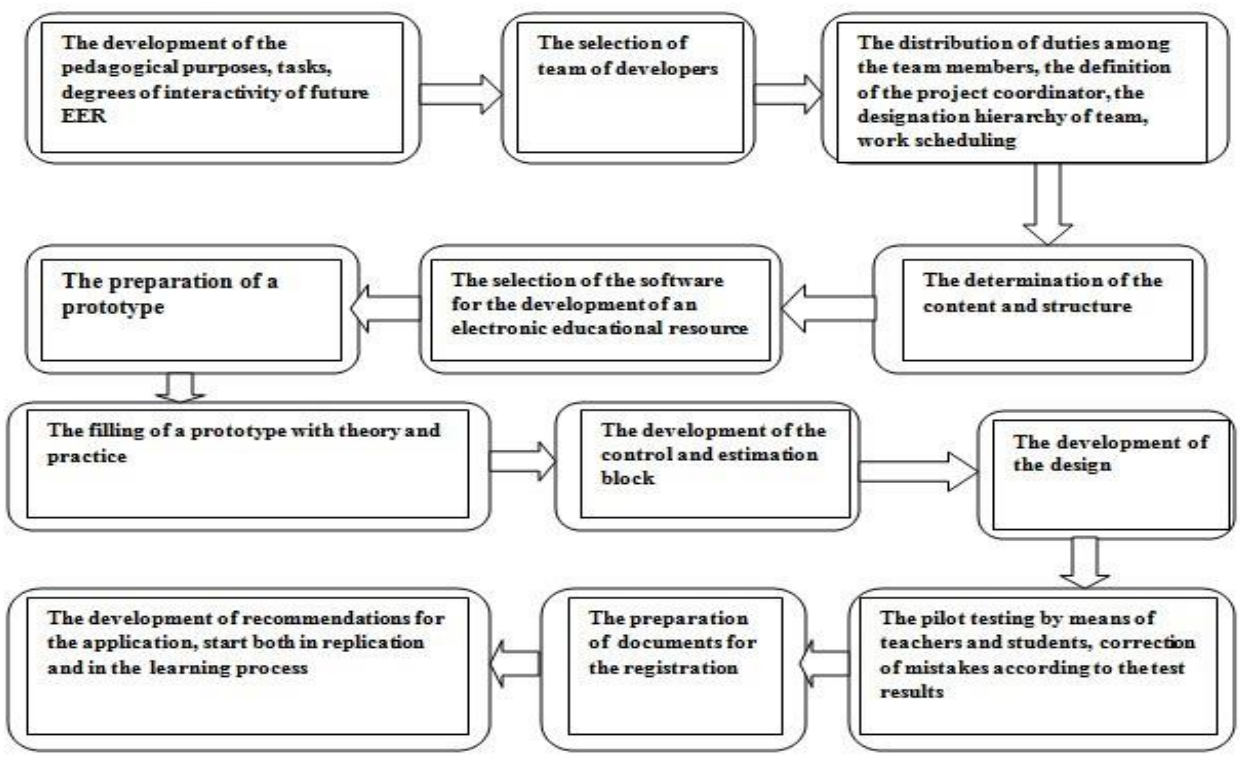

Fig. 1. The scheme of the EER standard development in a student's creative workshop.

\section{Results}

Having considered the stages of the project implementation in a creative workshop it is possible to share some observations of students work in this process. The process of students' personal growth in competitiveness in project and creative activities is implemented during the work on projects if such an activity systematically comes to the end with the presentation of the made educational product on condition of the competitive spirit between students and if they defend their projects in public. It is important to carry out an external assessment and a self-assessment of creative projects periodically to motivate students for interactive work not only in the team, but also within the workshop.

The continuous involvement of students into activity of a creative workshop and its efficiency promotes increase in the internal motivation adequate to a self-assessment of personal and professional qualities. When performing the professional tasks which require a high level of responsibility, students will be mobilized for overcoming difficult situations, development of non-standard decisions that are very important at high-rise construction.

The construction of high-rise and wide-span buildings requires high-quality team work therefore, it is important to immerse the students as future builders in professional activity since the junior course of education because at the end of their study they can make the qualitative specialists capable to get good positions.

In modern conditions of modernization of the higher education then perhaps it is essential to increase the quality of the higher engineering education when carrying out 
system-oriented project and creative activities to the students' personal growth in competitiveness. For this purpose, at the choice of the content of students' project and creative activities in a creative workshop, the conditions of the person-centered and competency-based approaches will be created. This choice depends on the teacher, who is the head of a creative workshop, on the subject or an occupational cycle, but it has to contain a possibility of professional activity modeling. At the same time a special attention has to be paid to forms and methods of students' project and creative activities for the introduction of elements of competitive spirit and the competition into this activity. The competitive spirit shouldn't worsen the emotional atmosphere of project teams and the whole workshop in general.

The lecturer is necessary to enter competitive elements of activity with special care if he wants to keep the friendly atmosphere and command spirit. Also the system monitoring where indicators and criteria of expert assessment, mutually assessment and self-esteem of students are implemented as the main acquired competences, and assessment of dynamics of their growth and development is obligatory in this process.

\section{Conclusions}

Thus, the structure of a creative workshop for higher education institutes in construction allowing to increase learning efficiency of students for the most responsible professional directions, including the " High-rise and Wide-span Buildings and Constructions" direction has been presented.

\section{References}

1. N.I. Pak, Projective approach in teaching as an information process: monograph (Krasnoyarsk, 2008)

2. E.L. Makarova, Interactive educational technologies in competency-oriented educational process: monograph (Sputnik, Moscow, 2010)

3. O.V. Solnyshkova, Engineering education 19, 8-15 (2016)

4. O. Solnyshkova, I. Makarikhina, IOP Conference Series: Earth and Environmental Science 90,012022 (2017)

5. O.V. Solnyshkova, I.M. Makarikhina, The world of science, culture, education 63(2), 157-159 (2017)

6. E.N. Rydanova, Izvestia Volgograd State Pedagogical University 1, 55-57 (2006)

7. P.S. Chubik, A.I. Chuchalin, M.A. Soloviev, O.M. Zamyatin, Issues of education 2, 188-208 (2013)

8. O.V. Mitchenchenkova, Education and self-development 5, 63-68 (2009)

9. R.S. Safin, New technologies for training engineers of construction specialties: monograph (KGASA, Kazan, 2000)

10. E.F. Shimorina, Motivation, self-actualization of students of Russian universities: monograph (Sputnik, Moscow, 2008)

11. I. V. Ilin, A.I. Levina, O Yu. Iliashenko, MATEC Web of Conferences, 106, 08066 (2017) DOi-10.1051/matecconf/201710608066

12. V. V. Gluhov, I. V. Ilin, Lecture Notes in Computer Science, 8638, 509- 518 (2014) DOi-10.1007/978-3-319-10353-2_46 